\title{
Front Matter: Volume 10342
}

, "Front Matter: Volume 10342," Proc. SPIE 10342, Optical Technologies for Telecommunications 2016, 1034201 (28 April 2017); doi: 10.1117/12.2279729

SPIE Event: XIV International Scientific and Technical Conference on Optical SPIE. Technologies in Telecommunications, 2016, Samara, Russian Federation 


\title{
PROCEEDINGS OF SPIE
}

\section{Optical Technologies for Telecommunications 2016}

\author{
Vladimir A. Andreev \\ Anton V. Bourdine \\ Vladimir A. Burdin \\ Oleg G. Morozov \\ Albert H. Sultanov \\ Editors
}

\section{2-24 November 2016 \\ Samara, Russian Federation}

\section{Organized by}

Povolzhskiy State University of Telecommunications and Informatics

(Russian Federation)

Ufa State Aviation Technical University (Russian Federation)

Kazan National Research Technical University (Russian Federation)

Published by

SPIE 
The papers in this volume were part of the technical conference cited on the cover and title page. Papers were selected and subject to review by the editors and conference program committee. Some conference presentations may not be available for publication. Additional papers and presentation recordings may be available online in the SPIE Digital Library at SPIEDigitallibrary.org.

The papers reflect the work and thoughts of the authors and are published herein as submitted. The publisher is not responsible for the validity of the information or for any outcomes resulting from reliance thereon.

Please use the following format to cite material from these proceedings:

Author(s), "Title of Paper," in Optical Technologies for Telecommunications 2016, edited by Vladimir A. Andreev, Anton V. Bourdine, Vladimir A. Burdin, Oleg G. Morozov, Albert H. Sultanov, Proceedings of SPIE Vol. 10342 (SPIE, Bellingham, WA, 2017) Seven-digit article CID Number.

ISSN: 0277-786X

ISSN: 1996-756X (electronic)

ISBN: 9781510611337

ISBN: 9781510611344 (electronic)

Published by

SPIE

P.O. Box 10, Bellingham, Washington 98227-0010 USA

Telephone +1 3606763290 (Pacific Time) · Fax +1 3606471445

SPIE.org

Copyright @ 2017 , Society of Photo-Optical Instrumentation Engineers.

Copying of material in this book for internal or personal use, or for the internal or personal use of specific clients, beyond the fair use provisions granted by the U.S. Copyright Law is authorized by SPIE subject to payment of copying fees. The Transactional Reporting Service base fee for this volume is $\$ 18.00$ per article (or portion thereof), which should be paid directly to the Copyright Clearance Center (CCC), 222 Rosewood Drive, Danvers, MA 01923. Payment may also be made electronically through CCC Online at copyright.com. Other copying for republication, resale, advertising or promotion, or any form of systematic or multiple reproduction of any material in this book is prohibited except with permission in writing from the publisher. The CCC fee code is $0277-786 \mathrm{X} / 17 / \$ 18.00$.

Printed in the United States of America.

Publication of record for individual papers is online in the SPIE Digital Library.

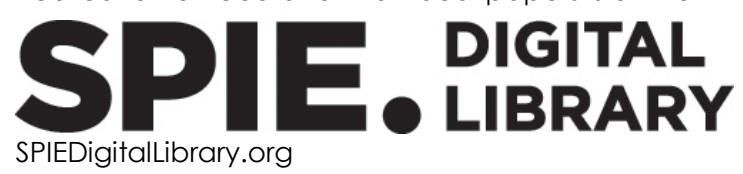

Paper Numbering: Proceedings of SPIE follow an e-First publication model. A unique citation identifier (CID) number is assigned to each article at the time of publication. Utilization of CIDs allows articles to be fully citable as soon as they are published online, and connects the same identifier to all online and print versions of the publication. SPIE uses a seven-digit CID article numbering system structured as follows:

- The first five digits correspond to the SPIE volume number.

- The last two digits indicate publication order within the volume using a Base 36 numbering system employing both numerals and letters. These two-number sets start with $00,01,02,03,04$, 05, 06, 07, 08, 09, OA, OB ... OZ, followed by 10-1Z, 20-2Z, etc. The CID Number appears on each page of the manuscript. 


\title{
Contents
}

\author{
vii Authors \\ ix Conference Committee \\ xi Introduction
}

SESSION 1 OPTICAL TELECOMMUNICATION TECHNOLOGIES AND SYSTEMS

1034202 Design of graded refractive index profile for silica multimode optical fibers with improved effective modal bandwidth for short-distance laser-based multi-Gigabit data transmission over "O"-band [10342-4]

1034203 Blocking probability in the hose-model optical VPN with different number of wavelengths [10342-5]

1034204 Design of MDM channel precision positioning scheme at the end of a few-mode optical fiber with enlarged core diameter [10342-6]

1034205 Influence of fiber bends on mode-dependent loss and mode coupling in mode division multiplexing systems [10342-10]

1034206 Cognitive optical networks: architectures and techniques [10342-11]

1034207 Design of low DMD few-mode optical fibers with extremely enlarged core diameter providing nonlinearity suppression for operating over "C"-band central region [10342-19]

1034208 The latest achievements in the development of the concept of radio- and optical systems quasiparticle based on Feynman integrals [10342-20]

1034209 Experimental demonstration of high-speed data transmission based on Gaussian pulses for IR-UWB radio-over-fiber systems [10342-27]

10342 OA Experimental study of wireless part of laboratory bench, implementing IR-UWB radio-overfiber system [10342-28]

$10342 \mathrm{OB}$ Comparison of propagation of vortex and non-vortex laser beams in a random medium [10342-32]

10342 OC Spinor-based approach on wave processes in optical fiber (Invited Paper) [10342-34]

10342 OD Optical frequency modulated pulse power losses, caused by optical fiber material dispersion [10342-39]

10342 OE Fiber material dispersion effect on a matched compression of an optical pulse with frequency modulation [10342-41] 
10342 OF Simulation and analysis of mode staff excitation during "O"-band optical signal launching to graded multimode fiber with large central defect of refractive index profile via standard singlemode fiber [10342-43]

10342 OG Redistribution of the laser beam power using diffractive optical elements [10342-45]

$10342 \mathrm{OH} \quad$ Investigation of characteristics of semiconductor optical amplifiers as a multifunctional devices for systems radio over fiber [10342-53]

\section{SESSION 2 PASSIVE AND ACTIVE COMPONENTS OF OPTICAL TELECOMMUNICATION}

10342 Ol Action of a generalized parabolic (aspheric) lens in different optical models [10342-1]

10342 0J Generation and conversion of mode beams and their polarization states [10342-12]

10342 OK Investigation of the characteristics of fiber optic delay lines with different types of optical emission intensity modulation [10342-13]

$10342 \mathrm{OL} \quad$ Modeling of nebula viewing broadband and narrowband filters based on $\mathrm{TiO}_{2}-\mathrm{SiO}_{2}$ multilayers [10342-21]

10342 OM Necessary conditions for a nonlinear few-mode excitation of modes in single-mode optical fiber [10342-23]

10342 ON Dispersion characteristics of step index single mode optical fiber with Kerr nonlinearity [10342-25]

1034200 Infrared reflective coatings for building and automobile glass windows for heat protection [10342-26]

10342 OP Constructive functional principles and control objectives executed with the device for optical signal splitting and chirping [10342-29]

$103420 Q \quad$ Optical signal splitting and chirping device modeling [10342-30]

10342 OR Tight focusing of laser light propagated through subwavelength micropolarizer using Fresnel zone plate [10342-31]

10342 OS Determination the allowable error to adjustment of a diffractive optical element and the accuracy demanded to set the parameters of the focused beam [10342-35]

10342 OT Simulation of temporal integration of optical signals with photonic crystal nanobeam cavities [10342-40]

10342 OU Modeling of the diffraction of the focused pulsed laser beam on a binary phase plate [10342-42]

10342 OV Morphology and optical properties of thin CdTe films [10342-44]

10342 OW Quasi-interferometric scheme improved by fiber Bragg grating written on macrostructure defect in silica multimode optical fiber operating in a few-mode regime [10342-47] 
10342 OX Technique for writing of fiber Bragg gratings over or near preliminary formed macrostructure defects in silica optical fibers [10342-48]

\section{SESSION 3 ONE-DIMENSION AND MULTI-DIMENSION OPTICAL SIGNALS DATA PROCESSING}

10342 OY Geometrical optics solutions of the inverse problem of focusing laser light into plane regions [10342-3]

$103420 Z$ Phase recovery algorithm in coherent homodyne optical systems [10342-7]

1034210 Image analysis in unmanned aerial vehicle on-board system for objects detection and recognition with the help of energy characteristics based on wavelet transform [10342-8]

1034211 The use of global image characteristics for neural network pattern recognitions [10342-15]

1034212 Surface plasmon polaritons generated by radial polarized laser beam on silver nano-ring [10342-17]

1034213 Processing multidimensional optical signals of video surveillance for speed measurement of extensional objects [10342-22]

1034214 Formation of optical signals based on eigenfunctions of double finite Hankel transform of order m [10342-24]

1034215 Software for analysis of the process of formation of the catalytic mask in the off-electrode plasma [10342-37]

\section{SESSION $4 \quad$ FIBER OPTIC SENSORS AND SENSOR NETWORKS}

1034216 Diffractive polarization illuminator for a two-axis fiber-optic angle sensor [10342-18]

1034217 Fiber-optic Bragg sensors with special spectrum shapes for climatic test systems [10342-38]

1034218 Methods and technique of manufacturing silica graded-index fibers with a large central defect of the refractive index profile for fiber-optic sensors based on few-mode effects [10342-46]

1034219 A practical approach to the development of aircraft GTE's noise suppression system on the base of fiber optic sensors [10342-49]

$103421 \mathrm{~A} \quad$ Microwave photonic system for instantaneous frequency measurement based on principles of "frequency-amplitude" conversion in fiber Bragg grating and additional frequency separation (Invited Paper) [10342-54]

10342 1B Photonic system for spectrum analysis of SHF-band signals based on stimulated Mandelstam-Brillouin scattering [10342-55] 
10342 1C Dependence of the optical cable stiffness on the hydrophobic filling at low temperatures [10342-16]

10342 ID Detection of splices of optical fibers with low loss [10342-36]

$10342 \mathrm{IE}$ The method for a measurement of the excess fiber length on the cable delivery length by using the polarization reflectometry [10342-50]

$10342 \mathrm{lF} \quad$ Application of remote fiber test system for distributed temperature measurement on overhead power lines [10342-51]

10342 IG Statistical characteristics of excess fiber length in loose tubes of optical cable [10342-56]

SESSION 6 PROBLEMS OF TRAINING ON OPTICAL TELECOMMUNICATION SCIENCE TOPICS

$10342 \mathrm{lH}$ Interactive educational technologies as a method of communicative competency development of optical and fiber optic communication systems specialists [10342-9]

$1034211 \quad$ Advanced training of specialists in area of fiber-optic communication lines maintenance [10342-14] 


\section{Authors}

Numbers in the index correspond to the last two digits of the seven-digit citation identifier (CID) article numbering system used in Proceedings of SPIE. The first five digits reflect the volume number. Base 36 numbering is employed for the last two digits and indicates the order of articles within the volume. Numbers start with 00, 01, 02, 03, 04, 05, 06, 07, 08, 09, OA, OB...0Z, followed by 10-1Z, 20-2Z, etc.

Abdrakhmanova, Guzel I., 09, OA, OP, OQ

Alekhin, Ivan N., $1 \mathrm{C}$

Ali, R. Z., 00

Andreev, Vladimir A., 07, OW, 0X, 1G, 11

Andreev, Vladimir A., 1 A

Andrianova, Anna V., 09, OA, OP, OQ

Bagmanov, Valeriy Kh., OC

Bielak, Robert, $0 \mathrm{G}$

Biryukov, Vladimir $V_{\text {., }}$ OK

Bourdine, Anton $V_{\text {., }}$ 02, 04, 07, OF, OM, ON, OW, OX, 18

Bukashkin, Sergey A., $\mathrm{OH}, 11$

Burdin, Vladimir A., 07, OF, OH, OM, ON, OW, OX, 18 , 1C, 1E

Butt, M. A., OL, 00

Buzov, Alexander L., $\mathrm{OH}$

Buzova, Maria A., 11

Chernov, Andrei A., OD, OE

Dashkov, Michael V., $\mathrm{OH}, 1 \mathrm{~F}$

Dashkov, Victor M., IF

Demidov, Vladimir V., OF, 18

Denisenko, Evgeniy P., 17

Denisenko, Pavel E., 17

Diyazitdinov, Rinat R., 13

Dmitriev, Daniil S., 1B

Dmitriev, Eugeniy $\vee$., OF

Dukelskii, Konstantin $V_{\text {., OF, } 18}$

Elyutin, V. V., OL

Evtushenko, Alexander S., 07, OW, OX

Faskhutdinov, Lenar M., OW, OX, 19, 1 A

Fomchenkov, S. A., OL, 00

Gavrilov, Pavel V., 1B

Gavryushin, Sergey A., $1 G$

Gizatulin, Azat R., 05

Golyeva, Elena $\vee ., 18$

Grachev, Vladimir V., OK

Grakhova, Elizaveta P., 09, OA, OP, OQ

Grebeshkov, Alexander Y., 06

Habib, M., 00

Halikov, Rashid H., 07

Husnutdinova, Marina N., $1 \mathrm{H}$

Ibragimov, R. Z., 0 Z

Ignatyev, A. V., OU

Ishmyarov, Arsen A., 09, OA, OP, OQ

Ivanov, Alexander A., IA

Ivanov, Dmitry V., OD, OE

Ivanov, Vladimir A., OD, OE

Kafarova, Anastasia M., OW, OX

Kapustin, Sergey A., OK
Karpeev, S. V., OJ

Kazakov, Vadim S., OX

Kazanskiy, Nikolay L., 00, OS, OT

Kazarov, Vitali Yu., 17

Kazbaeva, Dinara A., 1D

Kharitonov, Sergey I., OY

Khokhlov, Alexander $V_{\text {., }} 18$

Khonina, Svetlana N., OB, OL, 16

Kirilenko, Mikhail S., OB, 14

Kisselev, Anton E., 1D

Kolpakov, V. A., OV, 15

Komarov, Alexander V., 18

Komissarov, Arkadiy M., ID

Konkin, Nikita A., OD

Kotlyar, Maria $V_{\text {., }} \mathrm{OR}$

Kotlyar, Victor V., OR, 12

Kozlova, Elena S., 12

Krasnov, S. V., OU

Krichevskiy, S. V., 15

Kulyas, Maksim O., 11

Kulyas, Oleg L., 11

Kutlieva, Gulnaz R., OP, OQ

Kuznetzov, Artem A., OW, OX, 17, 19, 1A

Liedl, Gerhard, OG

Lobin, Sergey G., OK

Loshkarev, Aleksey S., 11

Lyasheva, S. A., 10

Lyubopytov, Vladimir S., 05

Makarov, Igor A., 1B

Markushin, M. A., 15

Matrosova, Alexandra S., 18

Matveeva, Tatiana U., $1 \mathrm{H}$

Medvedev, M. V., 10

Meshkov, Ivan K., 09, OA, OP, OQ

Minaeva, Alina YU., OF, OW, OX, 18

Morozov, Gennady A., 19, 1A, 1B

Morozov, Oleg G., OW, 0X, 17, 19, 1A, 1B

Murzin, Serguei P., OG, OS

Nalimov, Anton G., OR

Nasibullin, Aidar R., OE

Nikulina, Tatiana G., $1 \mathrm{C}$

Nureev, Ilnur I., OW, OX, 19

O'Faolain, Liam, OR

Osadchiy, Igor S., $1 \mathrm{H}$

Ovchinnikov, Vladimir $\mathrm{V} ., \mathrm{OE}$

Paranin, V. D., 16

Podlipnov, V. V., OV

Popov, Boris V., $1 G$

Popov, Victor B., $1 G$ 
Porfirev, Alexey P., OB

Potapov, A. A., 08

Praporshchikov, Denis E., OF, IC

Raevskii, Alexey S., OK

Rassadin, A. E., 08

Roslyakov, Alexander $\vee ., 03$

Ryabova, Maria I., OD, OE

Ryabova, Natalia V., OD, OE

Sakhabutdinov, Airat Zh., 19

Salikhov, Aydar I., 1D

Sarvarova, Lutsiya M., 19, 1B

Serafimovich, Pavel G., OT

Sevruk, Nikita L., OW, OX

Shaporin, Andrey A., 13

Shleymovich, M. P., 10

Stafeev, Sergey S., OR

Sultanov, Albert Kh., 05, 09, OA, OC, OP, OQ

Talipov, Anvar A., 1B

Ter-Nersesyants, Egishe V., OF, 18

Ullah, A., 00

Ustinov, A. V., Ol

Ustinov, Sergey V., 18

Vasilets, Alexander A., OW, OX

Vasin, Nikolay N., 13

Vazhdaev, Michael A., $1 G$

Vedenkin, Denis A., OE

Vinogradov, Vasiliy Yu., 19

Vinogradova, Irina L., 09, OA, OP, OQ

Volkov, Kirill A., $\mathrm{OH}$

Voronkov, Andrey A., 11

Voronkov, Grigory S., OA

Yantilina, Liliya Z., OP, OQ

Zastela, Mikhail Yu., 17

Zhdanov, Ruslan R., 1D

Zhukov, Alexander E., 02, OF 


\title{
Conference Committee
}

\author{
Conference Chairs
}

Vladimir A. Andreev, Povolzhskiy State University of Telecommunications and Informatics (Russian Federation) Vladimir A. Burdin, Povolzhskiy State University of Telecommunications and Informatics (Russian Federation)

Anton V. Bourdine, Povolzhskiy State University of Telecommunications and Informatics (Russian Federation)

Oleg G. Morozov, Kazan National Research Technical University (Russian Federation)

Albert H. Sultanov, Ufa State Aviation Technical University (Russian Federation)

Program Committee

S.A. Babin, Institute of Automation and Electrometry, Siberian Branch of the Russian Academy of Sciences (Russian Federation)

V.H. Bagmanov, Ufa State Aviation Technical University (Russian Federation)

M.V. Dashkov, Povolzhskiy State University of Telecommunications and Informatics (Russian Federation)

I.R. Gabitov, University of Arizona (United States)

S.F. Glagolev, The Bonch-Bruevich Saint - Petersburg State University of Telecommunications (Russian Federation)

I.V. Grigorov, Povolzhskiy State University of Telecommunications and Informatics (Russian Federation)

M.P. Fedoruk, Novosibirsk State University (Russian Federation)

G.I. Il'in, Kazan National Research Technical University (Russian Federation)

D.A. Kachkov, "Svyazstroy-4" (Russian Federation)

N.L. Kazanskiy, Image Processing Systems Institute (Russian Federation)

O.E. Nanii, Lomonosov Moscow State University (Russian Federation)

I.I. Nureev, Kazan National Research Technical University (Russian Federation)

R. Llorente, Universidad Politecnica de Valencia (Spain)

D. Plettemeier, Technische Universität Dresden (Germany)

A.S. Raevskii, Nizhniy Novgorod State Technical University (Russian Federation)

A.I. Salikhov, Ufa State Aviation Technical University (Russian Federation)

A.V. Shipulin, Technische Universität Darmstadt (Germany) 
I. Tafur Monroy, Danmarks Tekniske Universitet (Denmark)

S.K. Turitsyn, Aston University (United Kingdom)

I.L. Vinogradova, Ufa State Aviation Technical University

(Russian Federation)

K.A. Volkov, Povolzhskiy State University of

Telecommunications and Informatics (Russian Federation)

A.A. Voronkov, Povolzhskiy State University of

Telecommunications and Informatics (Russian Federation) 


\title{
Introduction
}

This volume contains a selection of reports presented at the 14th International Conference on Optical Technologies for Telecommunications. The conference was held 22-24 November 2016 at Povolzhskiy State University of Telecommunications and Informatics, Samara, Russian Federation.

The conference covered a large range of problems in optical technologies in telecommunications. We have no doubt that the proceedings from this conference will be helpful for both scientists and specialists working in the field of telecommunication technologies.

\author{
Vladimir A. Andreev \\ Anton V. Bourdine \\ Vladimir A. Burdin \\ Oleg G. Morozov \\ Albert H. Sultanov
}


Proc. of SPIE Vol. 10342 1034201-12 Downloaded From: https://www.spiedigitallibrary.org/conference-proceedings-of-spie on 25 Apr 2023
Terms of Use: https://www.spiedigitallibrary.org/terms-of-use 